\title{
Ontogeny of drug metabolism and transport: new data derived by innovative approaches
}

\author{
Bianca van Groen ${ }^{1}$, Karel Allegaert ${ }^{2}$, Dick Tibboel ${ }^{1}$, and Saskia De wildt ${ }^{3}$ \\ ${ }^{1}$ Erasmus MC - Sophia Children's Hospital \\ ${ }^{2} \mathrm{KU}$ Leuven \\ ${ }^{3}$ Radboud Institute of Health Sciences, Radboud University Medical Center
}

May 5, 2020

\begin{abstract}
Drug disposition in children is impacted by developmental changes in drug absorption, distribution, metabolism and excretion. This mandates the need for dosing regimens specifically tailored to children. Yet, there are gaps in the knowledge on these developmental changes, for example regarding hepatic and renal drug transport and drug metabolism, putting children at risk for subtherapeutic or toxic drug exposure. Pediatric drug research is faced with ethical and analytical challenges. This review addresses how these knowledge gaps can be filled and challenges can be overcome by using innovative study designs.
\end{abstract}

\section{Main text}

\section{Introduction}

Drug disposition in neonates, infants and children is impacted by development and growth. This includes developmental changes, i.e. ontogeny, in drug metabolism and drug transport.[1] Several information gaps on these developmental changes remain, bringing children at risk of subtherapeutic or toxic drug exposure. Hence, pediatric drug research to unravel and understand these developmental changes is highly needed, but is often considered complex - and sometimes even impossible - because of perceived challenges and burdens. Studies to delineate the age-related variation in drug metabolism and transport are often nontherapeutic, which makes these studies ethically challenging. The small blood and tissue sample volumes inherent to pediatric studies further pose practical challenges. Nevertheless, although pediatric drug research is considered complex and requires specific expertise, it is certainly not impossible.

The aim of this review is to show how innovative approaches (see Figure 1) allowed to elucidate important information gaps in ontogeny of drug transport and metabolism to illustrate the relevance of both in vitro as well as in vivo data, with the ultimate goal to improve drug therapy in pediatrics.

\section{Membrane transporters}

\section{How does membrane transporter expression change with age?}

Transporters are membrane-bound proteins present in the apical and basolateral membranes of organs such as the liver and kidney.[2] Their biological role is the bidirectional trafficking of substrates across membranes, making them critical determinants of tissue and cellular substrate disposition. Moreover, they act in concert with drug metabolizing enzymes to maintain homeostatic balance for endogenous substrates and to facilitate 
the detoxification and elimination of exogenous substrates, such as drugs and food toxins.[3] As a result of developmental changes in key transporters and enzymes, levels of exogenous and endogenous substrates may change as children grow, impacting normal physiology as well drug disposition and effect.[3]

In 2015 a review on the human ontogeny of drug transporters, it was concluded that huge knowledge gaps remain for pediatrics, and that, to achieve safe and effective drug therapy for children, it is crucial to elucidate developmental patterns of transporter mRNA and protein expression.[2] At that time, the data were mainly available from mRNA expression studies as there were analytical challenges regarding the quantification of protein levels. By advances in the use of liquid Chromatography with tandem mass spectrometry (LCMS/MS) allowing quantification of the protein expressions of a variety of drug transporters in only a small amount of tissue, also pediatric proteomics data became available. $[4,5]$

For both hepatic and renal transporters, age-related variation in protein expression of clinically relevant transporters has now been studied.[6-9] Transporter protein expression show different developmental patterns: e.g. increasing, decreasing or stable across the pediatric age range. These developmental patterns appear to be both isoform- and organ-dependent. Interestingly, most differences in transporter expression for hepatic transporters were found between the fetal and adult age groups, and for renal transporters between infants $<2$ years and adults, indicating that major changes in transporter protein expression occur in early life. More specifically for hepatic transporters, the sample size and age ranges in a study fromPrasad et al [5] were complimentary to a study from van Groen et al [6]. Prasad et al included 4 neonates, 19 infants, 32 children, 14 adolescents and 41 adults, whereas van Groen et al mainly included fetuses $(\mathrm{n}=36)$, preterm neonates $(\mathrm{n}=12)$ and term neonates $(\mathrm{n}=10)$. Both studies found that organic cation transporter 1 (OCT1), multi-drug resistance 1 (MDR1) and multidrug resistance-associated protein 3 (MRP3) increased with age. In a study from $\mathrm{Li}$ et al with 43 renal samples from children, adolescents and adults no age-related change in transporter protein expression were found[9], in contrast to the findings from Cheung and van Groen et al [8]. This discrepancy is likely explained by the fact that the study from Li et al had almost no samples from neonates and infants $<2$ years (i.e. 1 sample $<1$ year and 12 samples $1-<12$ year), which is the age range in which the most developmental changes were noticed by Cheung and van Groen et al . Interestingly, in addition to renal samples, Li et al also included 26 paired hepatic samples (a subset from Prasad et al [5]), and confirmed that the transporter expression ontogeny was organ dependent.[9] For other major organs like the intestine, pediatric protein expression data are lacking to date.[10]

The observations described above show that the transporter substrates disposition is subject to age-related changes. This impacts the efficacy and safety of pediatric drug therapy, which statement is supported by a study concluding that hepatic OCT1 ontogeny partly explained the lower clearance of its substrate morphine in neonates and infants compared to adults.[11] For renal transporters, however, it is more complex to delineate, as renal excretion of drugs is not only driven by active tubular secretion by transporters but also by glomerular filtration, which also changes with age. As children grow and develop, the glomerular filtration rate (GFR) matures, reaching $50 \%$ of adult values by 2 months and $90 \%$ of adult values by 1 year of age.[12] Thus, observed age-related changes in pharmacokinetics (PK) of renal transporter substrates are likely due to a combination of both maturation in transporter expression and GFR.

\section{Potential underlying mechanisms for transporter ontogeny}

It has been reported that there are differences in maturational patterns between mRNA and protein transporter expression. [6, 8] This interesting finding may aid to understand the underlying mechanisms of these patterns. Alternative splicing, a process that increases the diversity of products (splice variants) from a single gene, appears a potential underlying mechanism for maturational changes in organic anion transporter protein B1 (OATP1B1) expression, as the gene expression of a fair amount of splice variants was associated with age.[13] The total gene expression quantified by quantitative reverse transcription polymerase chain reaction (qRT-PCR) could be derived from a mixture of different splice variants of the targeted gene, also including splice variants that may not translate into protein.[14] Quantitative proteomics measures the actual expression of the protein of interest, hence alternative splicing could partly explain the lack of correlation 
between mRNA and protein expression, especially when a correlation is found in adults but not in children or vice versa .

More specifically, age-related variation in expression of solute carrier organic anion transporter 1B1 (SLCO1B1) splice variants may have implications for children, as most of these splice variants were predicted to result in truncated isoforms of the OATP1B1 transporter.[13] The functionality of the transporter is thought to be partly dependent on the number of transmembrane regions. As the truncated isoforms have fewer transmembrane regions, this could affect the functionality of the transporter in children, and with that the disposition of its endogenous and exogenous substrates. Furthermore, the localization of a transporter is a critical determinant of activity and correct functionality, which is partly determined by posttranslational changes, such as glycosylation.[15] The truncated SLCO1B1 isoforms may lack one or more of the N-glycosylation sites, which may lead to an inappropriate localization as non-glycosylated OATP1B1 is retained within the endoplasmic reticulum, e.g. not being present on the cell membrane.[16]

Another interesting observation is that the expressions over age of several transporters are strongly correlated. $[6,8]$ For example, the expressions of renal transporters OAT1 and OAT3 were strongly correlated.[8] As these expressions are impacted by age, the underlying mechanism for ontogeny may be the same. OAT1 and OAT3 are located in adjacent regions on chromosome 11.[17] Moreover, they are both positively regu-

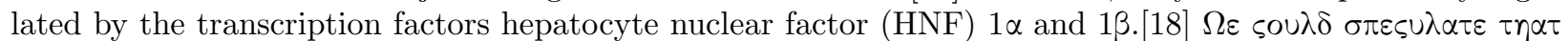
$\mathrm{HN} \Phi 1 \alpha$ and $1 \beta$ are also impacted by age, giving rise to the developmental patterns of OAT1 and OAT3. However, the relationship between transcription factors maintaining basal expression level, like the HNF family, and transporter expression, is still largely unknown, let alone the impact of age on transcription factors.

\section{Methods and study design to study ontogeny of drug transport}

Currently, there is a lack of harmonized practices in the implementation of LC-MS/MS based proteomic quantification, leading to variability in reported abundances of the same proteins.[19,20] Using such data to subsequently simulate PK may introduce unexpected bias, especially when in vivo PK data to validate the simulations are lacking. Not only the analytical method may present differences, also the data may be reported in different units. For example, it was found for hepatic transporters that crude membrane yield per amount of tissue was higher in fetuses than in term newborns. [6] Therefore, ontogeny patterns may not be similar when describing transporter protein expression per gram crude membrane instead of per gram of tissue. However, in literature these units are used inconsistently, as consensus is lacking on how to report proteomic data.

More specifically for renal transporters, sample preparation and data interpretation are further complicated by the fact that the kidney consists of cortex and medulla. Renal transporters are primarily located in the kidney's proximal tubules, which are enriched in the cortex, whereas the medulla is enriched with distal/collecting tubules. The relative composition of cortex versus medulla in frozen tissue could vary depending on sample collection and dissection, resulting in confounded interpretation of ontogeny data. For adult renal transporters, normalization to the housekeeping protein aquaporin 1, located specifically in the proximal tubule, is often used. The literature data on aquaporin 1 in children is conflicting, as aquaporin 1 displays a developmental pattern with $50 \%$ of adult expression at birth [21, 22], restricting its use as a housekeeping protein in pediatric studies. Interestingly, $L i$ et al recently studied aquaporin 1 protein expression in 43 human samples from 0.5 to 35 years of age and could not identify an age-related change in expression. [9] They first used the ratio of this protein to aquaporin 2, which is located in the distal/collecting tubules, to exclude tissues that were contaminated with medulla (based on the statistical Grubb's test to identify outliers). Thereafter, they normalized the renal transporter expression to aquaporin 1 to study ontogeny patterns. 


\section{Challenges and future perspectives for the ontogeny of transporters}

While the current studies significantly contributed to our understanding on age-related changes in transporter expression, there are still future perspectives to continue this work. First, although the current studies cover the entire age range, the protein expression of renal transporters in neonates is understudied, as the two available studies both only included one neonate. $[8,9]$ In addition, the unexplained interindividual variability in protein expression within age groups for both renal and hepatic transporters is distinct.[6-9] In addition to age, other potential factors, such as the use of co-medications and inflammation, can influence the transporter expression and thereby contribute to the expression variability.[23, 24] The impact of acute and chronic inflammation on transporter expression and activity is related to the activity of multiple proinflammatory cytokines that can activate or inhibit involved nuclear receptors or transcription factors.[25] The exact mechanism remains unknown. Similarly, certain medications and environmental toxins could lead to activation of nuclear receptor pathways, and could, therefore, influence the transporter expression.[25, 26] The underlying causes of death of our tissue donors are heterogeneous and so are the exposures to drugs and environmental toxins. Lastly, using post-mortem tissue is faced with challenges as the amounts of degradation in mRNA and protein levels from death to freezing are not known. Degradation may vary among samples, and may result in reduced absolute levels and increased variability in expression level measurements. The interplay of age with these other co-variates merits further elucidation.

Also genomic variation can impact mRNA and/or protein transporter expression. For hepatic transporters one study was unable to identify such a relationship in a cohort mainly focused on fetuses and newborns[6], although the selected genetic variants have been shown earlier to affect mRNA and/or protein expression in adults or older children. This finding may be explained by the small sample size, but could also partly be explained by the interplay between development and genetics. For example, in a previous study, SLC22A1181C $>$ T in adult samples correlated with OCT1 protein expression[27], but this was not confirmed in the pediatric cohort[6]. The OCT1 expression was low in fetuses, potentially obscuring a possible effect of genetic variants. Interestingly, on the other hand, SLC22A1 genotype (giving rise to the OCT1 transporter) is related to tramadol disposition in preterm infants, similar to adults.[28] This suggests that, although protein levels are low, the SLC22A1 genotype can result in significant differences in protein activity in neonates. In the cohort of van Groen et al OATP1B1 protein expression was stable within SLCO1B1 diplotypes.[6] In contrast, Prasad et al. showed higher protein expression in neonates versus older children/adults with the $S L C O 1 B 1 * 1 \mathrm{~A} /{ }^{*} 1 \mathrm{~A}$ haplotype.[5] Thus, it remains important to include genotype when analyzing developmental patterns. Furthermore, the interaction between genetic variants and age should be further studied.

This review focuses on the kidney and liver, but transporters are also abundant in other major organs, such as the gastro-intestinal tract, and sanctuary sites including the brain.[29] The same holds for drug metabolizing enzymes. Developmental patterns of transporter and drug metabolizing enzyme isoforms appear to be organdependent. [9] Hence, an understanding of the ontogeny of multiple transporters, drug metabolizing enzymes and tissues in parallel would provide a more holistic view on entire human development.[30]

To cope with the lack of consensus for conducting proteomic studies, a recently published white paper discussed current practices and provided recommendations towards harmonization of practices.[31] More specifically, recommendations were given on specific proteomic quantification techniques, sample preparation and quality controls, as well as documenting of tissue weight and the originating organ section. For further method development, housekeeping proteins should be further validated to normalize for technical variability. Hence, to enable comparison and combining data originating from various laboratories, it is advised to follow these and future recommendations.

Importantly, the impact of a transporter on the disposition of a substrate is determined by its functional activity. It is widely accepted to use mRNA and protein expression data as a surrogate parameter for the functional activity of a transporter.[2] However, there may be discrepancies between expression and activity, as already introduced before. Therefore, ex vivo ontogeny should preferably be validated by in vivo data. Earlier, tazobactam PK data were used to validate the ontogeny profiles of the renal transporters 
OAT1/3.[10] Another approach to estimate transporter maturation is to distract age-specific GFR estimations from reported total renal clearance values of a specific renal tubular transporter substrate. Willmann et al . determined the renal tubular MDR1 maturation by distracting estimated GFR from digoxin total renal clearance, a MDR1 substrate.[32] Next, for the MDR1 substrate rivaroxaban plasma concentrations were simulated over the pediatric age range. The assumption was made that MDR1 transport is the rate-limiting factor in the tubular secretion of both digoxin and rivaroxaban. These examples aid in creating confidence to incorporate the ex vivo data for predicting pediatric PK.

\section{In vivo pediatric microdosing and microtracing studies}

\section{Oral bioavailability}

Validated markers to phenotype a drug metabolism route can be used to study developmental changes of drug metabolizing enzymes in vivo . Most drugs are administered to children orally[33], hence the oral bioavailability is an important determinant for systemic exposure. The traditional study design to obtain data on oral bioavailability entails a cross-over study design where an oral or intravenous (IV) dose of a drug are administered on two separate occasions in random order in the same individual, with a wash-out period in between. This design is ethically and practically challenging, as children need to be exposed twice to therapeutic doses with extensive blood sampling, without any benefit for themselves. As international ethical guidelines prohibit studies that may not provide benefit to children and that pose more than minimal risk and burden over those daily encountered, alternative approaches are needed. To overcome challenges faced with such pediatric PK studies, microdosing/microtracing studies with $\left[{ }^{14} \mathrm{C}\right]$ labelled substrates constitute an interesting alternative. A microdose is a very small, sub-therapeutic dose of a drug $\left(<1 / 100^{\text {th }}\right.$ of the therapeutic dose or $<100 \mu \mathrm{g}$ ), which is unlikely to result in pharmacological effects or adverse events. [34, 35] A radioactive label $\left[{ }^{14} \mathrm{C}\right]$ allows ultra-sensitive quantification of extremely low plasma-concentrations by accelerator mass spectrometry (AMS), for which only 10-15 $\mu$ l plasma is required.[36, 37] The radiation dose associated with a $\left[{ }^{14} \mathrm{C}\right]$ microdose is safe as it is below $1 \mu$ Sievert. This is much lower than the yearly background exposure (2.5 mSievert/year in the Netherlands), a computed tomography (CT)-scan of the head (1200 $\mu$ Sievert), or a chest x-ray (12 $\mu$ Sievert).[38] Given these considerations, microdosing studies are considered as non-therapeutic trials with minimal burden that carry minimal risk.[39]

Interestingly, to assess the oral bioavailability, a microdose can be concurrently administered with a therapeutic dose, where the microdose is then called a microtracer. This elegant and innovative study design enables measurement of both intravenous (IV) and oral disposition, allowing to determine the oral bioavailability of a drug, limiting the extensive blood sampling needed for a cross-over study and limiting the day-today variability.[40, 41] There are two pediatric studies reported using this study design. First, age related changes in oral bioavailability of paracetamol (acetaminophen or AAP) as a measure of glucuronidation and sulfation was studied in stable, critically ill children, who were receiving IV therapeutic paracetamol for clinical purposes and had an indwelling arterial catheter enabling blood sampling in place.[40] Fifty children (median age 6 months [range 3 days-6.9 years]) received an oral $\left[{ }^{14} \mathrm{C}\right] \mathrm{AAP}$ microtracer $(3.3[2.0-3.5] \mathrm{ng} / \mathrm{kg}$; $64[41-71] \mathrm{Bq} / \mathrm{kg}$ ). They showed that, with increasing age, plasma and urinary AAP-glucuronide/AAP and AAP-glucuronide/AAP-sulfation ratios significantly increased by four fold, while the AAP-sulfation/AAP ratio significantly decreased. In other words, this showed that a developmental change of AAP metabolism from mainly sulfation in neonates to glucuronidation in older children.[40] The mean enteral bioavailability of AAP in this population was $72 \%$ (range, 11-91\%).[41]

The second study used the benzodiazepine midazolam as a well-validated cytochrome $\mathrm{P} 450$ (CYP) 3A probe to unravel the ontogeny of CYP3A that is abundant in both the intestine and liver and contributes to the first-pass metabolism of many orally administered drugs.[1, 42, 43] Forty-six stable, critically ill children (median age 9.8 [range 0.3 - 276.4] weeks; three quarters of the 46 subjects were $0-6$ months old) received a single oral $\left[{ }^{14} \mathrm{C}\right]$ midazolam microtracer $(58[40-67] \mathrm{Bq} / \mathrm{kg}) .[44]$ The bioavailability of midazolam was $66 \%$ with a large range of $25-85 \%$ for which no explanatory covariates could be identified. These findings were in line with the expected CYP3A ontogeny where older children and adults are thought to have a higher 
CYP3A activity and with that a lower oral bioavailability[43] than the population in the microtracer study, and vice versa for preterm neonates. The median of $66 \%$ [44] was lower than the reported median value of $92 \%$ in preterm neonates[45] and higher than the reported median value of $21 \%$ in older children of $1-18$ years.[46] Also the reported mean $\pm \mathrm{SD}$ of $28 \pm 7 \%$ in adults is lower.[47] The oral bioavailability was also highly variable in previous pediatric studies. In preterm neonates, the oral bioavailability ranged from 67 to 95\%[45] and from 12 to 100\%[48], and in children 1-18 years from 2 to 78\%.[46] Other factors than age may also influence the oral bioavailability of midazolam. A previous study from Vet and Brussee et al. found a significant impact of organ failure on the midazolam clearance[23], with the greatest impact in children with [?]3 failing organs, and inflammation as reflected by CRP.[23, 49]

Also, besides the oral bioavailability of both AAP and midazolam is impacted by drug absorption processes like intestinal surface area[50], permeability[51], gastric emptying time, intestinal transit time, the production of bile fluid[52] and organ blood flow to the intestines and liver[53]. The influences of age and (critical) illness on these processes should be studied to further explain the variability in oral bioavailability of AAP and midazolam.

The study design with an oral $\left[{ }^{14} \mathrm{C}\right]$ microtracer was shown successful for safely studying the oral bioavailability of AAP and midazolam in children. To ultimately improve the safety and efficacy of pediatric drug therapy, we recommend to consider study designs with microdoses for minimal risk PK studies and microtracer studies to elucidate oral bioavailability.

\section{Dose linearity of a microdose}

A prerequisite of extrapolating the PK of microdose directly to a therapeutic dose, is that the PK of a microdose of a certain drug/compound is linear to the PK of a therapeutic dose. [54, 55] Lack of linearity may occur, for example, when a therapeutic dose saturates drug metabolism pathways, plasma protein binding and/or active transporters. $[55,56]$ Because of the maturational differences in drug metabolism and transport, results from adults should not be extrapolated directly to the pediatric population. A very elegant approach was taken to study the dose-linearity of a $\left[{ }^{14} \mathrm{C}\right]$ midazolam microdose [57]; the PK parameters of an isolated $\left[{ }^{14} \mathrm{C}\right]$ microdose were compared with the PK parameters of a $\left[{ }^{14} \mathrm{C}\right]$ microtracer administered concurrently or even mixed with a therapeutic drug dose. This study supported dose-linearity of the PK of the isolated $\left[{ }^{14} \mathrm{C}\right]$ midazolam microdose to the PK of the $\left[{ }^{14} \mathrm{C}\right]$ midazolam microtracer.

\section{$\left[{ }^{14} \mathrm{C}\right]$ microtracer study to create metabolite profiles of midazolam}

In children, the rate of a metabolic route may be different from that in adults due to underdevelopment of a certain pathway, but they may even require alternative metabolic routes. In the latter case, other metabolites may be present that are not identified during drug development in adults. This could lead to unsafe drug therapy as children may be exposed to a metabolite of which the action and PK are unknown. Interestingly, by using $\left[{ }^{14} \mathrm{C}\right]$ microtracers, a drug can be concurrently administrated with a therapeutic dose, and therefore metabolites can be identified and quantified with a radioactivity exposure of even less than $0.1 \mu \mathrm{Ci}$. $[34,35]$ These analytical advances allow us to overcome ethical and analytical challenges with regard to radioactivity exposure in pediatrics. $[58,59]$ A proof of concept study with a $\left[{ }^{14} \mathrm{C}\right]$ midazolam microtracer showed that in children metabolite profiles of midazolam were safely created and the routes of excretion were safely studied.[60] This approach is promising for first-in-child studies to delineate age-related variation in drug metabolite profiles.

\section{Feasibility}

Earlier studies have shown that it is feasible to use a $\left[{ }^{14} \mathrm{C}\right]$ labelled substrate to phenotype a certain drug metabolism pathway [40,41, 60-63]; not only were the PK findings in line with expectations, but importantly, parents allowed their children to participate in these studies with a consent rate of around $50 \%$. This informed consent rate is in agreement with the consent rate of other non-therapeutic studies in pediatric intensive care.[64] Most often, professionals express ethical concerns regarding the radioactive exposure, including the 
expectation that parents will not allow their children to participate in such studies. The authors state that the experience during conversations with parents was that consent was not necessarily refused due to the radioactivity exposure as they had received a good understanding of the negligible exposure compared with the yearly background exposure. The reason for refusing consent was more often the burden of procedures in addition to the clinical care. This is not surprising, as for clinical reasons they may have to undergo a number of painful and stressful procedures (median 11 [IQR $=5-23]$ per day established in a previous study[65]), which has impact on the parents as well.

\section{Challenges and perspectives for pediatric microdosing and microtracing studies}

Over the past decade, regulatory legislations for drug development in pediatric patients have been passed worldwide. These regulations dramatically increased the number of drugs tested in children. In 2014-2015, the U.S. Food and Drug Administration (FDA) reviewed 274 pediatric study plans, whereas in 2012-2013 the number was only 20.[66] This trend was also seen in the EU, with 31 new drugs/indications authorized for use in children in 2004-2006, versus 86 in 2012-2016.[67] In spite of this impressive increase, still a large amount of drugs enter the market without being licensed for pediatric use. Since the entry of the Pediatric Regulation and up to 31 December 2015, eighty-nine new medicines were centrally authorized for pediatric use, which was only $26 \%$ out of all 352 new medicines.[67] This is partly because many pediatric studies failed[68], but also due to limitations of this regulation: when the prediction of the risk of toxicity of a new compound is not adequate, the regulation allows European Medicines Agency (EMA) and U.S. Food and Drug Administration (FDA) to waive the studies in the youngest children.[69] Yet, in clinical practice, the drug will be prescribed off-label with its inherent risks. Although off-label is not off-evidence, as pediatric PK data for existing drugs are increasingly available in literature, there are still huge knowledge gaps. Especially for drugs under development, a microdosing study could be of benefit by studying the PK and the metabolite profile, respectively, of a new compound in children without risk of toxicity. These studies are considered as non-therapeutic trials with minimal burden that carry minimal risk, which is echoed by the Dutch legislation, EU regulation and the U.S. FDA.[70]

However, despite positive experiences with microdose studies, professionals may still resist using this approach in children or other vulnerable populations. Doses are rather derived from physiologically based pharmacokinetic (PBPK) models (see paragraph 'Using PBPK models to predict pediatric drug exposure and its challenges') or allometry, but these approaches are suboptimal as the biological data underlying the PBPK models for special populations still show large knowledge gaps despite the literature data and new data presented in this thesis. This leaves these populations at a higher risk of toxicity or therapeutic failure. Therefore, microdosing studies may be of great value in pediatric drug development and are now suggested in the 2019, FDA (draft) Guidance: General Clinical Pharmacology Considerations for Neonatal Studies for Drugs and Biological Products Guidance for Industry.[71] Lastly, these approaches would also allow studying the PK or metabolite profiles in other vulnerable special populations like pregnant women, critically ill or elderly.

\section{Study design, sample sizes, data sharing}

Combining samples from various laboratories or research groups is interesting for the pediatric population, as tissues for ex vivostudies are scarce and sample sizes for in vivo studies are small. Moreover, pooling samples beforehand avoids lab-to-lab variability and likely result in more reliable and complete results, hence research groups should collaborate rather than compete. Also, to further accelerate data generation, international biobanks would be of added value to overcome the scarcity of pediatric tissue.

In addition, similar collaborative efforts should be taken to overcome challenges in recruitment of patients for in vivo studies due to low number of eligible patients, suboptimal pediatric trial infrastructure and study design challenges. This often results in a long recruitment period or even failure to fulfill recruitment targets. Pediatric trial networks may overcome these challenges by providing a framework to facilitate collaboration and combine resources and expertise to conduct and manage studies. Examples are the IMI2 
project to develop a European wide Paediatric Clinical Trial Network, Conect4Children for Europe and, the Pediatric Clinical Trials Network and iACT both in the U.S. Existing government-supported research infrastructures in Europe, such as BBMRI (biobanking), ELIXIR (data), EATRIS (drug development) and ECRIN (clinical trials), which have traditionally focused on adults, should collaborate to integrate pediatrics, with the ethical and practical specificities outlined throughout this review. An important side note: these pediatric trial networks and infrastructures may create new challenges, such as accounting for differences in clinical practice between countries and hospitals, and the extensive time and discussion needed to reach consensus about study designs. Pharmaceutical companies, academia and regulatory institutes work together in these initiatives, but their scientific goals/aims and procedures for pediatric trials may differ.

In terms of data availability, initiatives for data sharing platforms[20] are encouraged in which all raw data of published articles are made freely available. Currently, certain scientific journals have made it mandatory for authors to submit the raw dataset along with the manuscript[72], which is a positive advancement.

\section{Predicting pediatric drug exposure and dosing recommendations}

\section{Using PBPK models to predict pediatric drug exposure and its challenges}

Protein and gene expression data on drug metabolism and drug transport may be leveraged in PBPK models alongside with pediatric physiology. These models are complex multi-compartment kinetic models that allow prediction of drug exposure in a specific target population. These models rely on in vitro data and physiological parameters and can subsequently be explored based on in vivo data. PBPK models are also increasingly used in drug development to optimize clinical trial design and doses, also for pediatric trials.[73] Fifteen percent of all new drug application submissions to the FDA between 2008 and 2017 that included PBPK analyses supported the evaluation of pediatric-related issues such as initial dose recommendation for clinical trials.[74] Several pediatric clinical studies have been replaced with or informed by PBPK modeling.[75, 76] For example, models have been used to set a starting dose in a clinical trial with eribulin in children and adolescents 6-18 years of age, and to bridge from immediate to extended release quetiapine formulations in children and adolescents 10-17 years of age.[75, 77]

Another area where PBPK modeling could be helpful is for drug-drug interactions (DDIs). Hospitalized children may be exposed to up to 10 different drugs.[78] With that, DDIs are inevitable, for which recommendations from adult DDI studies are often extrapolated to the pediatric population. In a systematic literature review, the numbers of interactions for 24 drug pairs were compared between 31 pediatric studies and 33 adult studies. The number of DDIs differed: in 15 of the 33 cases, the fold number of DDIs were higher ( $>1.25$ - fold) for children than for adults, and in 8 of the 33 cases, the fold number of DDIs were lower $(<0.8$ - fold $)$ in children than in adults. For example, digoxin plus amiodarone and lamotrigine plus valproate resulted in a 2.18- fold higher and a 0.58- fold lower exposure, respectively, in children compared with adults due to the underlying maturation of processes involved in drug disposition. These findings warn us that simple extrapolation of adult DDI studies to the pediatric population can under- of overpredict the impact of a DDI with subtherapeutic or toxic exposure to a drug as a result. PBPK modeling is a powerful tool to explore and quantitatively predict DDIs, also in a pediatric population.[75]

The use of PBPK models to predict pediatric drug exposure comes with important limitations, though. The gene expression, protein expression and/or activity of some genes involved in drug disposition are correlated, and for these cases expression data are used in PBPK models as a surrogate for determining activity. However, these correlations are most often shown in adult populations. A previous study found that the fraction of highly glycosylated OATP1B3 increased with age.[79] Because post-transcriptional and post-translational modifications like glycosylation of transporters[79] may be subject to age-related changes, it could well be that gene and protein expression are correlated in adults but not in children. Hence, these correlations should not be extrapolated directly from adults to children as this could lead to inaccurate predictions of drug disposition. This also accounts for the fraction of a parent drug that is metabolized or transported by a certain protein[80], which often is assumed to be the same for children and adults. Yet, the 
maturation of enzymes and transporters may change their relative contributions in the disposition.[80, 81]

In the end, the success of PBPK simulation in children depends highly on knowledge of the drug disposition pathways and the availability ofex vivo/in vitro data. As knowledge gaps remain next to the new available data, routine use of PBPK modeling in prediction of pediatric drug disposition should be done carefully until these knowledge gaps are filled. Nevertheless, PBPK modeling currently helps us understand drug metabolism and transport pathways, and the impact of a change in a certain pathway (e.g. maturation).

\section{Dosing recommendations in clinical practice}

The increase in pediatric research has helped enormously in understanding how PK of a variety of drugs is different in various age groups, giving rise to pediatric-specific dosing recommendations. But to implement this knowledge in clinical practice comes with challenges. First, prescribers may remain unaware of dosing recommendations published in scientific literature or lack understanding and trust in PK studies and their subsequent dosing simulations. The Dutch Knowledge Center on Pharmacotherapy in Children (NKFK) hereby serves as an example on how this knowledge translation gap can be bridged, as it has developed a pediatric drug formulary based on best available evidence from registration data, investigator-initiated research, professional guidelines, and clinical experience.[82] That this approach is valuable is shown by the recent extension of the formulary to country-specific editions in Germany, Austria and Norway. Second, the current pediatric dosing recommendations are often only based on PK data assuming that the target concentration for effect is the same in children and adults. Yet, these target concentrations may well be different in children as PD could also be subject to age-related changes. [83] These dosing recommendations should therefore preferably be validated prospectively, especially when they are only based on PK data. Depending on the confidence of the dosing recommendation (e.g. the underlying data), this can be done in clinical practice with opportunistic PK sampling or with clinical data collection of PD parameters of specific interest. Or, when the confidence is low, in a pediatric trial where the former dosing regimen can be compared to the new dosing regimen based on PK and PD parameters.

Using population PK and PBPK models to simulate and predict the optimal drug exposure may lead to complex dosing regimens and consequently logistical problems in clinical practice. In hospital, for example, nurses are used to administer drugs to patients at fixed times. Also for patients outside the hospital, therapy compliance may be negatively affected if they have to take drugs at varying times. Moreover, some doses are not feasible to administer, for example $1 / 8$ of a tablet is hard to prepare, and pediatric formulations are missing. [84] Furthermore, the electronic health care systems are limited in terms of integrating complex models where covariates are included to provide the best dosing regimens, followed by integrating this in clinical care. [85, 86] Lastly, clinical staff may have little understanding of complex population PK models, and may lack trust in these dosing regimens. Nevertheless, efforts are being made to accelerate implementation, such as the calculator of the Dutch Pediatric Formulary that allows clinical staff to include covariates to get the optimal dose. Furthermore, startups create their own electronic systems to integrate complex dosing regimens that can be used in clinical care parallel to the electronic health care system.[86]

\section{Other innovative techniques/approaches}

Regarding ex vivo studies, opportunities exist for unraveling the ontogeny of drug disposition on the level of protein/mRNA expression in 'fresh' tissue instead of post-mortem tissue. These include the use of organoids that represent three-dimensional culture systems in which stem cells grow and represent the native physiology of the cells in vivo. [87] When using tissue-derived hepatic, renal or intestinal stem cells from children, the organoid may reflect the pediatric native physiology and allow to study the expression of transports or drug metabolizing enzymes. Organoids can also be used to unravel regulatory pathways. Two-dimensional models of e.g. intestinal organoids may provide opportunity to study drug metabolism and transporter activity in a situation that even closer resembles the in vivo situation. Another innovative approach could be the use of exosomes, which are circulating extracellular vesicles secreted by organs.[88] These exosomes are present in the blood and contain proteins, mRNA and microRNA derived from the originating organ and can be used 
to measure transporter and drug metabolizing enzyme expression.[88] It is not known, however, whether organoids and exosomes keep their age-specific properties outside a human body, which is a prerequisite for studying age-related changes in expression/activity of transport and metabolism.

Another approach involves in vivo assessment of drug metabolizing enzyme or transport activity through endogenous substrates as biomarkers, for example 6b-hydroxycortisol or 4b-hydroxycholesterol for assessment of CYP3A activity.[89] Interestingly, studies in adults have identified endogenous substrates as potential markers to phenotype the activity of transporters in vivo, for example thiamine for OCT1 and dehydroepiandrosterone sulfate (DHEAS) for OATP1B1/3.[89] This approach does not require administration of an external marker and the levels could be measured with a single rather than multiple blood draws, thereby overcoming one of the challenges in pediatric research. This approach is not used often yet, as reference values of endogenous substrate levels in children are lacking. These values cannot be simply extrapolated from values in adults, as homeostatic levels in children may differ from those in adults. For example, DHEAS levels at birth are high and decrease drastically over the first month of life, followed by a more progressively decrease until the first $6^{\text {th }}$ month of life.[90] Hence, specific reference values for these endogenous substrates for various age groups should be gained first.

Global metabolomics studies can help identify biomarkers for enzymes and transporters, also in a pediatric population. This approach was taken by Tay-Sontheimer et al who identified a urinary biomarker to phenotype CYP2D6 activity.[91] Although that specific biomarker was not structurally identified, this example shows that metabolomic methods are useful in revealing biomarkers in children.

\section{Conclusion}

To conclude, our understanding of ontogeny of drug metabolism and transport in children has increased, supported by e.g. the expansion of knowledge in the ontogeny of transporters, especially those in the liver and kidney. This increased knowledge has significant implications for understanding drug disposition of substrates in the younger age groups. Pediatric $\left[{ }^{14} \mathrm{C}\right]$ labeled microdosing and microtracing studies have been shown useful to study the PK of drugs used in children, like AAP and midazolam. Moreover, PBPK modeling helps us understand drug metabolism and transport pathways, and the impact of a change in a certain pathway but should be done carefully until knowledge gaps on ontogeny of drug disposition are filled. These results are of importance for pediatric drug development and current practice with the ultimate aim to improve pediatric drug therapy.

\section{Acknowledgements}

The authors thank K. Hagoort for editorial assistance.

\section{Conflict of interest statement}

Nothing to declare.

\section{Funding information}

No funding was received for this review. 


\section{References}

1. Kearns GL, Abdel-Rahman SM, Alander SW, Blowey DL, Leeder JS, Kauffman RE. Developmental pharmacology-drug disposition, action, and therapy in infants and children. N Engl J Med 2003; 349: 1157-67.

2. Brouwer KL, Aleksunes LM, Brandys B, Giacoia GP, Knipp G, Lukacova V, Meibohm B, Nigam SK, Rieder M, de Wildt SN, Pediatric Transporter Working G. Human ontogeny of drug transporters: review and recommendations of the pediatric transporter working group. Clin Pharmacol Ther 2015; 98: 266-87.

3. Nigam SK. What do drug transporters really do? Nat Rev Drug Discov 2015; 14: 29-44.

4. Mooij MG, van de Steeg E, van Rosmalen J, Windster JD, de Koning BA, Vaes WH, van Groen BD, Tibboel D, Wortelboer HM, de Wildt SN. Proteomic analysis of the developmental trajectory of human hepatic membrane transporter proteins in the first three months of life. Drug Metab Dispos 2016; 44: 1005-13.

5. Prasad B, Gaedigk A, Vrana M, Gaedigk R, Leeder JS, Salphati L, Chu X, Xiao G, Hop C, Evers R, Gan L, Unadkat JD. Ontogeny of hepatic drug transporters as quantified by LC-MS/MS proteomics. Clin Pharmacol Ther 2016; 100: 362-70.

6. van Groen BD, van de Steeg E, Mooij MG, van Lipzig MMH, de Koning BAE, Verdijk RM, Wortelboer HM, Gaedigk R, Bi C, Leeder JS, van Schaik RHN, van Rosmalen J, Tibboel D, Vaes WH, de Wildt SN. Proteomics of human liver membrane transporters: a focus on fetuses and newborn infants. Eur J Pharm Sci 2018; 124: 217-27.

7. Prasad B, Johnson K, Billington S, Lee C, Chung GW, Brown CD, Kelly EJ, Himmelfarb J, Unadkat JD. Abundance of Drug Transporters in the Human Kidney Cortex as Quantified by Quantitative Targeted Proteomics. Drug Metab Dispos 2016; 44: 1920-24.

8. Wun Kathy Cheung K, van Groen BD, Spaans E, van Borselen MD, A CJMdB, Simons-Oosterhuis Y, Tibboel D, Samsom JN, Verdijk RM, Smeets B, Zhang L, Huang SM, Giacomini KM, de Wildt SN. A comprehensive analysis of ontogeny of renal drug transporters: mRNA analyses, quantitative proteomics and localization. Clin Pharmacol Ther 2019.

9. Li CY, Hosey-Cojocari C, Basit A, Unadkat JD, Leeder JS, Prasad B. Optimized Renal Transporter Quantification by Using Aquaporin 1 and Aquaporin 2 as Anatomical Markers: Application in Characterizing the Ontogeny of Renal Transporters and Its Correlation with Hepatic Transporters in Paired Human Samples. AAPS J 2019; 21: 88.

10. Cheung KWK, van Groen BD, Burckart GJ, Zhang L, de Wildt SN, Huang SM. Incorporating Ontogeny in Physiologically Based Pharmacokinetic Modeling to Improve Pediatric Drug Development: What We Know About Developmental Changes in Membrane Transporters. J Clin Pharmacol 2019; 59 Suppl 1: S56-S69.

11. Emoto C, Johnson TN, Neuhoff S, Hahn D, Vinks AA, Fukuda T. PBPK Model of Morphine Incorporating Developmental Changes in Hepatic OCT1 and UGT2B7 Proteins to Explain the Variability in Clearances in Neonates and Small Infants. CPT Pharmacometrics Syst Pharmacol 2018; 7: 464-73.

12. Rhodin MM, Anderson BJ, Peters AM, Coulthard MG, Wilkins B, Cole M, Chatelut E, Grubb A, Veal GJ, Keir MJ, Holford NH. Human renal function maturation: a quantitative description using weight and postmenstrual age. Pediatr Nephrol 2009; 24: 67-76.

13. van Groen BD, Bi C, Gaedigk R, Staggs VS, Tibboel D, de Wildt SN, Leeder JS. Alternative Splicing of the SLCO1B1 Gene: An Exploratory Analysis of Isoform Diversity in Pediatric Liver. Clin Transl Sci 2020.

14. Zhang M, Liu YH, Chang CS, Zhi H, Wang S, Xu W, Smith CW, Zhang HB. Quantification of gene expression while taking into account RNA alternative splicing. Genomics 2018: DOI: 
10.1016/j.ygeno.2018.10.009.

15. Klaassen CD, Aleksunes LM. Xenobiotic, bile acid, and cholesterol transporters: function and regulation. Pharmacol Rev 2010; 62: 1-96.

16. Yao J, Hong W, Huang J, Zhan K, Huang H, Hong M. N-Glycosylation dictates proper processing of organic anion transporting polypeptide 1B1. PLoS One 2012; 7: e52563.

17. Kent WJ, Sugnet CW, Furey TS, Roskin KM, Pringle TH, Zahler AM, Haussler D. The human genome browser at UCSC. Genome Res 2002; 12: 996-1006.

18. Wang L, Sweet DH. Renal organic anion transporters (SLC22 family): expression, regulation, roles in toxicity, and impact on injury and disease. AAPS J 2013; 15: 53-69.

19. Wegler C, Gaugaz FZ, Andersson TB, Wisniewski JR, Busch D, Groer C, Oswald S, Noren A, Weiss F, Hammer HS, Joos TO, Poetz O, Achour B, Rostami-Hodjegan A, van de Steeg E, Wortelboer H, Artursson P. Variability in mass spectrometry-based quantification of clinically relevant drug transporters and drug metabolizing enzymes. Mol Pharm 2017.

20. Ladumor MK, Thakur A, Sharma S, Rachapally A, Mishra S, Bobe P, Rao VK, Pammi P, Kangne H, Levi D, Balhara A, Ghandikota S, Joshi A, Nautiyal V, Prasad B, Singh S. A repository of protein abundance data of drug metabolizing enzymes and transporters for applications in physiologically based pharmacokinetic (PBPK) modelling and simulation. Sci Rep 2019; 9: 9709.

21. Devuyst O, Burrow CR, Smith BL, Agre P, Knepper MA, Wilson PD. Expression of aquaporins-1 and -2 during nephrogenesis and in autosomal dominant polycystic kidney disease. Am J Physiol 1996; 271: F169-83.

22. Liu H, Wintour EM. Aquaporins in development - a review. Reprod Biol Endocrinol 2005; 3: 18.

23. Vet NJ, Brussee JM, de Hoog M, Mooij MG, Verlaat CW, Jerchel IS, van Schaik RH, Koch BC, Tibboel D, Knibbe CA, de Wildt SN, Skic. Inflammation and organ failure severely affect midazolam clearance in critically ill children. Am J Respir Crit Care Med 2016; 194: 58-66.

24. Le Vee M, Jouan E, Moreau A, Fardel O. Regulation of drug transporter mRNA expression by interferongamma in primary human hepatocytes. Fundam Clin Pharmacol 2011; 25: 99-103.

25. Evers R, Piquette-Miller M, Polli JW, Russel FGM, Sprowl JA, Tohyama K, Ware JA, de Wildt SN, Xie W, Brouwer KLR, International Transporter C. Disease-Associated Changes in Drug Transporters May Impact the Pharmacokinetics and/or Toxicity of Drugs: A White Paper From the International Transporter Consortium. Clin Pharmacol Ther 2018; 104: 900-15.

26. Prakash C, Zuniga B, Song CS, Jiang S, Cropper J, Park S, Chatterjee B. Nuclear Receptors in Drug Metabolism, Drug Response and Drug Interactions. Nuclear Receptor Res 2015; 2: 101178.

27. Nies AT, Koepsell H, Winter S, Burk O, Klein K, Kerb R, Zanger UM, Keppler D, Schwab M, Schaeffeler E. Expression of organic cation transporters OCT1 (SLC22A1) and OCT3 (SLC22A3) is affected by genetic factors and cholestasis in human liver. Hepatology 2009; 50: 1227-40.

28. Matic M, de Wildt SN, Elens L, de Hoon JN, Annaert P, Tibboel D, van Schaik RH, Allegaert K. SLC22A1/OCT1 Genotype Affects O-desmethyltramadol Exposure in Newborn Infants. Ther Drug Monit 2016; 38: 487-92.

29. DeGorter MK, Xia CQ, Yang JJ, Kim RB. Drug transporters in drug efficacy and toxicity. Annu Rev Pharmacol Toxicol 2012; 52: 249-73.

30. Smits A, Annaert P, Allegaert K. Drug disposition and clinical practice in neonates: cross talk between developmental physiology and pharmacology. Int J Pharm 2013; 452: 8-13. 
31. Prasad B, Achour B, Artursson P, Hop C, Lai Y, Smith PC, Barber J, Wisniewski JR, Spellman D, Uchida Y, Zientek MA, Unadkat JD, Rostami-Hodjegan A. Toward a Consensus on Applying Quantitative Liquid Chromatography-Tandem Mass Spectrometry Proteomics in Translational Pharmacology Research: A White Paper. Clin Pharmacol Ther 2019; 106: 525-43.

32. Willmann S, Becker C, Burghaus R, Coboeken K, Edginton A, Lippert J, Siegmund HU, Thelen K, Muck W. Development of a paediatric population-based model of the pharmacokinetics of rivaroxaban. Clin Pharmacokinet 2014; 53: 89-102.

33. Schirm E, Tobi H, de Vries TW, Choonara I, De Jong-van den Berg LT. Lack of appropriate formulations of medicines for children in the community. Acta Paediatr 2003; 92: 1486-9.

34. European Medicines Agency. ICH Topic M3 (R2) Non-Clinical Safety Studies for the Conduct of Human Clinical Trials and Marketing Authorization for Pharmaceuticals. 2008.

35. Food and Drug Administration US Department of Health and Human Services Guidance for Industry Investigators and Reviewers. Exploratory IND Studies. 2006.

36. Salehpour M, Possnert G, Bryhni H. Subattomole sensitivity in biological accelerator mass spectrometry. Anal Chem 2008; 80: 3515-21.

37. Vuong LT, Blood AB, Vogel JS, Anderson ME, Goldstein B. Applications of accelerator MS in pediatric drug evaluation. Bioanalysis 2012; 4: 1871-82.

38. Turner MA, Mooij MG, Vaes WH, Windhorst AD, Hendrikse NH, Knibbe CA, Korgvee LT, Maruszak W, Grynkiewicz G, Garner RC, Tibboel D, Park BK, de Wildt SN. Pediatric microdose and microtracer studies using 14C in Europe. Clin Pharmacol Ther 2015; 98: 234-7.

39. Ethical Considerations For Clinical Trials On Medicinal Products Conducted With The Paediatric Population - Recommendations of the ad hoc group for the development of implementing guidelines for Directive 2001/20/EC relating to good clinical practice in the conduct of clinical trials on medicinal products for human use 2008 .

40. Mooij MG, van Duijn E, Knibbe CA, Allegaert K, Windhorst AD, van Rosmalen J, Hendrikse NH, Tibboel D, Vaes WH, de Wildt SN. Successful Use of [14C]Paracetamol Microdosing to Elucidate Developmental Changes in Drug Metabolism. Clin Pharmacokinet 2017.

41. Kleiber N, Calvier E, Mooij MG, Krekels EHJ, Vaes WHJ, Tibboel D, Knibbe CAJ, de Wildt SN. Enteral Acetaminophen Bioavailability in Pediatric Intensive Care Patients Determined With an Oral Microtracer and Pharmacokinetic Modeling to Optimize Dosing. Crit Care Med 2019.

42. Hines RN. The ontogeny of drug metabolism enzymes and implications for adverse drug events. Pharmacol Ther 2008; 118: 250-67.

43. de Wildt SN, Kearns GL, Leeder JS, van den Anker JN. Cytochrome P450 3A: ontogeny and drug disposition. Clin Pharmacokinet 1999; 37: 485-505.

44. van Groen BD, Krekels EHJ, Mooij MG, van Duijn E, Vaes WHJ, Windhorst AD, van Rosmalen J, Hartman SJF, Hendrikse NH, Koch BCP, Allegaert K, Tibboel D, Knibbe CAJ, de Wildt SN. The oral bioavailability and metabolism of midazolam in stable critically ill children: a pharmacokinetic microtracing study. Accepted for publication in Clin Pharmacol Ther 2020.

45. Brussee JM, Yu H, Krekels EHJ, de Roos B, Brill MJE, van den Anker JN, Rostami-Hodjegan A, de Wildt SN, Knibbe CAJ. First-Pass CYP3A-Mediated Metabolism of Midazolam in the Gut Wall and Liver in Preterm Neonates. CPT: pharmacometrics \& systems pharmacology 2018; 7: 374-83.

46. Brussee JM, Yu H, Krekels EHJ, Palic S, Brill MJE, Barrett JS, Rostami-Hodjegan A, de Wildt SN, Knibbe CAJ. Characterization of Intestinal and Hepatic CYP3A-Mediated Metabolism of Midazolam in 
Children Using a Physiological Population Pharmacokinetic Modelling Approach. Pharmaceutical research 2018; 35: 182.

47. Brill MJ, van Rongen A, Houwink AP, Burggraaf J, van Ramshorst B, Wiezer RJ, van Dongen EP, Knibbe CA. Midazolam pharmacokinetics in morbidly obese patients following semi-simultaneous oral and intravenous administration: a comparison with healthy volunteers. Clin Pharmacokinet 2014; 53: 931-41.

48. de Wildt SN, Kearns GL, Hop WC, Murry DJ, Abdel-Rahman SM, van den Anker JN. Pharmacokinetics and metabolism of oral midazolam in preterm infants. Br J Clin Pharmacol 2002; 53: 390-2.

49. Ince I, de Wildt SN, Peeters MY, Murry DJ, Tibboel D, Danhof M, Knibbe CA. Critical illness is a major determinant of midazolam clearance in children aged 1 month to 17 years. Ther Drug Monit 2012; 34: 381-9.

50. Bai JPF, Burckart GJ, Mulberg AE. Literature Review of Gastrointestinal Physiology in the Elderly, in Pediatric Patients, and in Patients with Gastrointestinal Diseases. J Pharm Sci 2016; 105: 476-83.

51. Debotton N, Dahan A. A mechanistic approach to understanding oral drug absorption in pediatrics: an overview of fundamentals. Drug Discov Today 2014; 19: 1322-36.

52. Mooij MG, de Koning BA, Huijsman ML, de Wildt SN. Ontogeny of oral drug absorption processes in children. Expert Opin Drug Metab Toxicol 2012; 8: 1293-303.

53. Bjorkman S. Prediction of drug disposition in infants and children by means of physiologically based pharmacokinetic (PBPK) modelling: theophylline and midazolam as model drugs. Br J Clin Pharmacol 2005; 59: 691-704.

54. Lappin G, Kuhnz W, Jochemsen R, Kneer J, Chaudhary A, Oosterhuis B, Drijfhout WJ, Rowland M, Garner RC. Use of microdosing to predict pharmacokinetics at the therapeutic dose: experience with 5 drugs. Clin Pharmacol Ther 2006; 80: 203-15.

55. Bosgra S, Vlaming ML, Vaes WH. To Apply Microdosing or Not? Recommendations to Single Out Compounds with Non-Linear Pharmacokinetics. Clin Pharmacokinet 2016; 55: 1-15.

56. van Nuland M, Rosing H, Huitema ADR, Beijnen JH. Predictive Value of Microdose Pharmacokinetics. Clin Pharmacokinet 2019.

57. van Groen BD, Vaes WH, Park BK, Krekels EHJ, van Duijn E, Korgvee LT, Maruszak W, Grynkiewicz G, Garner RC, Knibbe CAJ, Tibboel D, de Wildt SN, Turner MA. Dose-linearity of the pharmacokinetics of an intravenous [(14) C]midazolam microdose in children. Br J Clin Pharmacol 2019.

58. Schadt S, Bister B, Chowdhury SK, Funk C, Hop C, Humphreys WG, Igarashi F, James AD, Kagan M, Khojasteh SC, Nedderman ANR, Prakash C, Runge F, Scheible H, Spracklin DK, Swart P, Tse S, Yuan J, Obach RS. A Decade in the MIST: Learnings from Investigations of Drug Metabolites in Drug Development Under the "Metabolites in Safety Testing" Regulatory Guidances. Drug Metab Dispos 2018.

59. Yu H, Bischoff D, Tweedie D. Challenges and solutions to metabolites in safety testing: impact of the International Conference on Harmonization M3(R2) guidance. Expert Opin Drug Metab Toxicol 2010; 6: 1539-49.

60. van Groen BD, van Duijn E, de Vries A, Mooij MG, Tibboel D, Vaes WHJ, de Wildt SN. Proof of concept: first pediatric $\left[{ }^{14} \mathrm{C}\right]$ microtracer study to create metabolite profiles of midazolam. Accepted for publication in Clin Pharmacol Ther 2020.

61. Mooij MG, van Duijn E, Knibbe CA, Windhorst AD, Hendrikse NH, Vaes WH, Spaans E, Fabriek BO, Sandman H, Grossouw D, Hanff LM, Janssen PJ, Koch BC, Tibboel D, de Wildt SN. Pediatric microdose study of [(14)C]paracetamol to study drug metabolism using accelerated mass spectrometry: proof of concept. Clin Pharmacokinet 2014; 53: 1045-51. 
62. Gordi T, Baillie R, Vuong le T, Abidi S, Dueker S, Vasquez H, Pegis P, Hopper AO, Power GG, Blood AB. Pharmacokinetic analysis of $14 \mathrm{C}$-ursodiol in newborn infants using accelerator mass spectrometry. J Clin Pharmacol 2014; 54: 1031-7.

63. Garner CR, Park KB, French NS, Earnshaw C, Schipani A, Selby AM, Byrne L, Siner S, Crawley FP, Vaes WH, van Duijn E, deLigt R, Varendi H, Lass J, Grynkiewicz G, Maruszak W, Turner MA. Observational infant exploratory [(14)C]-paracetamol pharmacokinetic microdose/therapeutic dose study with accelerator mass spectrometry bioanalysis. Br J Clin Pharmacol 2015; 80: 157-67.

64. Menon K, Ward R, Canadian Critical Care Trials G. A study of consent for participation in a nontherapeutic study in the pediatric intensive care population. J Med Ethics 2014; 40: 123-6.

65. Baarslag MA, Jhingoer S, Ista E, Allegaert K, Tibboel D, van Dijk M. How often do we perform painful and stressful procedures in the paediatric intensive care unit? A prospective observational study. Aust Crit Care 2019; 32: 4-10.

66. Department of Health and Human Services, Food and Drug Administration. Best Pharmaceuticals for Children Act and Pediatric Research Equity Act - Status Report to Congress. 2016.

67. European Medicines Agency. 10-year Report to the European Commission: General report on the experience acquired as a result of the application of the Paediatric Regulation (EMA/231225/2015). 2016.

68. Stiers JL, Ward RM. Newborns, one of the last therapeutic orphans to be adopted. JAMA Pediatr 2014; 168: $106-8$.

69. Food and Drug Administration. Guidance for Industry: How to Comply with the Pediatric Research Equity Act 2005.

70. Roth-Cline M, Nelson RM. Microdosing Studies in Children: A US Regulatory Perspective. Clin Pharmacol Ther 2015; 98: 232-3.

71. Food and Drug Administration. General Clinical Pharmacology Considerations for Neonatal Studies for Drugs and Biological Products Guidance for Industry - DRAFT. 2019.

72. Wilkinson MD, Dumontier M, Aalbersberg IJ, Appleton G, Axton M, Baak A, Blomberg N, Boiten JW, da Silva Santos LB, Bourne PE, Bouwman J, Brookes AJ, Clark T, Crosas M, Dillo I, Dumon O, Edmunds S, Evelo CT, Finkers R, Gonzalez-Beltran A, Gray AJ, Groth P, Goble C, Grethe JS, Heringa J, t Hoen PA, Hooft R, Kuhn T, Kok R, Kok J, Lusher SJ, Martone ME, Mons A, Packer AL, Persson B, Rocca-Serra P, Roos M, van Schaik R, Sansone SA, Schultes E, Sengstag T, Slater T, Strawn G, Swertz MA, Thompson M, van der Lei J, van Mulligen E, Velterop J, Waagmeester A, Wittenburg P, Wolstencroft K, Zhao J, Mons B. The FAIR Guiding Principles for scientific data management and stewardship. Sci Data 2016; 3: 160018.

73. Wang Y, Zhu H, Madabushi R, Liu Q, Huang SM, Zineh I. Model-Informed Drug Development: Current US Regulatory Practice and Future Considerations. Clin Pharmacol Ther 2019; 105: 899-911.

74. Grimstein M, Yang Y, Zhang X, Grillo J, Huang SM, Zineh I, Wang Y. Physiologically Based Pharmacokinetic Modeling in Regulatory Science: An Update From the U.S. Food and Drug Administration's Office of Clinical Pharmacology. In: Journal of Pharmaceutical Sciences, 2019.

75. Shebley M, Sandhu P, Emami Riedmaier A, Jamei M, Narayanan R, Patel A, Peters SA, Reddy VP, Zheng M, de Zwart L, Beneton M, Bouzom F, Chen J, Chen Y, Cleary Y, Collins C, Dickinson GL, Djebli N, Einolf HJ, Gardner I, Huth F, Kazmi F, Khalil F, Lin J, Odinecs A, Patel C, Rong H, Schuck E, Sharma P, Wu SP, Xu Y, Yamazaki S, Yoshida K, Rowland M. Physiologically Based Pharmacokinetic Model Qualification and Reporting Procedures for Regulatory Submissions: A Consortium Perspective. Clin Pharmacol Ther 2018; 104: 88-110.

76. Wagner C, Zhao P, Pan Y, Hsu V, Grillo J, Huang SM, Sinha V. Application of Physiologically Based Pharmacokinetic (PBPK) Modeling to Support Dose Selection: Report of an FDA Public Workshop on 
PBPK. CPT Pharmacometrics Syst Pharmacol 2015; 4: 226-30.

77. Johnson TN, Zhou D, Bui KH. Development of physiologically based pharmacokinetic model to evaluate the relative systemic exposure to quetiapine after administration of IR and XR formulations to adults, children and adolescents. Biopharm Drug Dispos 2014; 35: 341-52.

78. Dai D, Feinstein JA, Morrison W, Zuppa AF, Feudtner C. Epidemiology of Polypharmacy and Potential Drug-Drug Interactions Among Pediatric Patients in ICUs of U.S. Children's Hospitals. Pediatr Crit Care Med 2016; 17: e218-28.

79. Thomson MM, Hines RN, Schuetz EG, Meibohm B. Expression Patterns of Organic Anion Transporting Polypeptides 1B1 and 1B3 Protein in Human Pediatric Liver. Drug Metab Dispos 2016; 44: 999-1004.

80. Salem F, Johnson TN, Barter ZE, Leeder JS, Rostami-Hodjegan A. Age related changes in fractional elimination pathways for drugs: assessing the impact of variable ontogeny on metabolic drug-drug interactions. J Clin Pharmacol 2013; 53: 857-65.

81. Elmorsi Y, Barber J, Rostami-Hodjegan A. Ontogeny of Hepatic Drug Transporters and Relevance to Drugs Used in Pediatrics. Drug Metab Dispos 2016; 44: 992-8.

82. van der Zanden TM, de Wildt SN, Liem Y, Offringa M, de Hoog M, Dutch Paediatric Pharmacotherapy Expertise Network N. Developing a paediatric drug formulary for the Netherlands. Arch Dis Child 2017; 102: 357-61.

83. Anderson BJ, Holford NH. Understanding dosing: children are small adults, neonates are immature children. Arch Dis Child 2013; 98: 737-44.

84. Gerrard SE, Walsh J, Bowers N, Salunke S, Hershenson S. Innovations in Pediatric Drug Formulations and Administration Technologies for Low Resource Settings. Pharmaceutics 2019; 11.

85. Darwich AS, Ogungbenro K, Vinks AA, Powell JR, Reny JL, Marsousi N, Daali Y, Fairman D, Cook J, Lesko LJ, McCune JS, Knibbe C, de Wildt SN, Leeder JS, Neely M, Zuppa AF, Vicini P, Aarons L, Johnson TN, Boiani J, Rostami-Hodjegan A. Why has model-informed precision dosing not yet become common clinical reality? lessons from the past and a roadmap for the future. Clin Pharmacol Ther 2017; 101: 646-56.

86. Keizer RJ, Ter Heine R, Frymoyer A, Lesko LJ, Mangat R, Goswami S. Model-Informed Precision Dosing at the Bedside: Scientific Challenges and Opportunities. CPT Pharmacometrics Syst Pharmacol 2018; 7: 785-87.

87. Nantasanti S, de Bruin A, Rothuizen J, Penning LC, Schotanus BA. Concise Review: Organoids Are a Powerful Tool for the Study of Liver Disease and Personalized Treatment Design in Humans and Animals. Stem Cells Transl Med 2016; 5: 325-30.

88. Rodrigues D, Rowland A. From Endogenous Compounds as Biomarkers to Plasma-Derived Nanovesicles as Liquid Biopsy; Has the Golden Age of Translational Pharmacokinetics-Absorption, Distribution, Metabolism, Excretion-Drug-Drug Interaction Science Finally Arrived? Clin Pharmacol Ther 2019; 105: 1407-20.

89. Muller F, Sharma A, Konig J, Fromm MF. Biomarkers for In Vivo Assessment of Transporter Function. Pharmacol Rev 2018; 70: 246-77.

90. de Peretti E, Forest MG. Pattern of plasma dehydroepiandrosterone sulfate levels in humans from birth to adulthood: evidence for testicular production. J Clin Endocrinol Metab 1978; 47: 572-7.

91. Tay-Sontheimer J, Shireman LM, Beyer RP, Senn T, Witten D, Pearce RE, Gaedigk A, Gana Fomban CL, Lutz JD, Isoherranen N, Thummel KE, Fiehn O, Leeder JS, Lin YS. Detection of an endogenous urinary biomarker associated with CYP2D6 activity using global metabolomics. Pharmacogenomics 2014; 15: $1947-62$. 


\section{Figure legends}

Figure 1: An overview of innovative approaches to gather new data on ontogeny of drug metabolism and transport, and their results and implementation. These approaches are discussed in this review, and are supplemented with suggestions for future approaches.

Footnote: PK=pharmacokinetics, PBPK=physiologically based pharmacokinetic

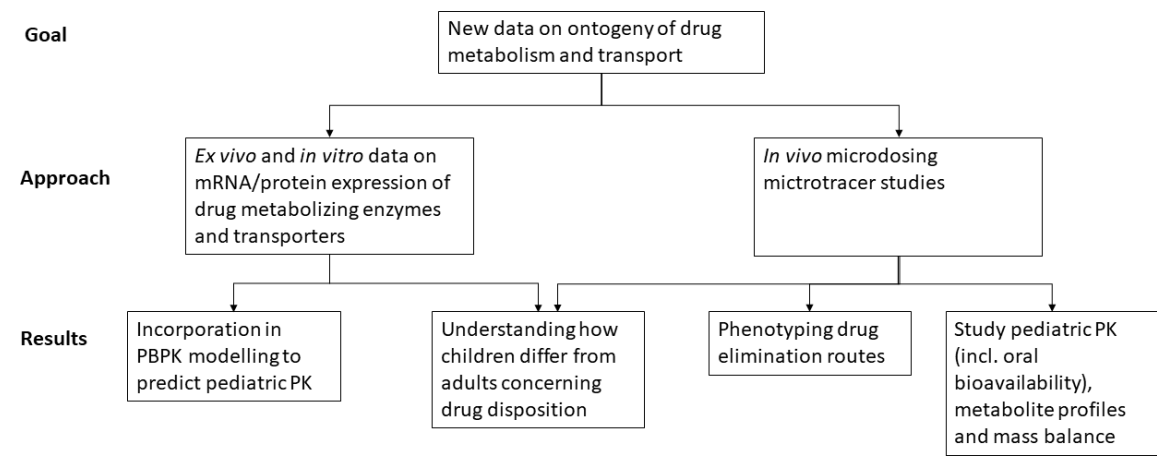

